\title{
Definition of an Effective Oral Appliance for the Treatment of Obstructive Sleep Apnea and Snoring: An Update for 2019
}

\author{
Kenneth Mogell, DMD, D. ABDSM (Chair) ${ }^{1}$; Norman Blumenstock, DDS, D. ABDSM ${ }^{2}$; Erika Mason, DDS, D. ABDSM, D. ACSDD; \\ Rosemarie Rohatgi, DMD, D. ABDSMㅜ; Srujal Shah, DDS, D. ABDSM ${ }^{5}$; David Schwartz, DDS, D. ABDSM (Board Liaison) ${ }^{6}$
}

\footnotetext{
${ }^{1}$ Florida Dental Sleep Disorders, ${ }^{2}$ Central Jersey Dental Sleep Medicine, ${ }^{3}$ Private Practice, ${ }^{4}$ San Diego Sleep Therapy, ${ }^{5}$ Spark Sleep Solutions, ${ }^{6}$ Sleep Better Chicagoland
}

\subsection{INTRODUCTION}

Oral appliance therapy (OAT) is effective for treating patients with snoring and obstructive sleep apnea (OSA). ${ }^{1}$ OAT can be an effective treatment for patients who prefer oral appliances over continuous positive airway pressure or who are unable to tolerate continuous positive airway pressure. ${ }^{2-7}$ The American Academy of Dental Sleep Medicine (AADSM) originally created a definition for an effective oral appliance in 2013. Since then, a large amount of scientific literature has been published focusing on oral appliances. Thus, the original definition was revisited to determine whether it was consistent with current scientific evidence and clinical practice. This article presents the updated definition of an effective oral appliance.

\subsection{BACKGROUND}

In February 2013, the AADSM convened a consensus conference to determine the definition of an effective oral appliance. ${ }^{8}$ This definition was formed in response to The Centers for Medicare and Medicaid Services publication of a Local Coverage Determination L33611, which defined an oral appliance quite narrowly. Prior to the consensus conference, a literature search was conducted which resulted in 113 articles to support the definition of an effective oral appliance. In March 2013, the AADSM Board of Directors approved this definition. $^{8}$

In November 2018, the AADSM convened a task force meeting to determine whether the original definition should be updated.

\subsection{METHODS}

In November 2018, the task force was asked to review the original consensus conference paper detailing the definition of an oral appliance, The Centers for Medicare and Medicaid Services definition of an effective oral appliance, and relevant recent scientific literature regarding oral appliances. Literature was gathered from PubMed, using the search terms from the
2013 consensus paper. ${ }^{8}$ Included articles were published from March 13, 2013 - October 24, 2018. Review articles were screened for full-text availability, relevance to OAT, and detailed discussion of OAT. Clinical trials were screened for full-text availability, relevance to OAT, and detailed definition of oral appliance(s) used. A total of 45 review articles and clinical trials were reviewed by the task force. After review of this literature, the task force recommended that the definition be updated.

A second literature search was conducted, using both the original search terms as well as keywords and $\mathrm{MeSH}$ terms associated with each change proposed. Articles were screened for relevance to the changes proposed by the task force. A total of 58 articles were included in the final review (articles were included if published between March 9, 2000 - January 10, 2019). After being asked to review these articles, the task force met to discuss the finalization of changes in February 2019.

\subsection{UPDATED DEFINITION}

The task force presented their updated definition to the AADSM Board of Directors in March 2019. The final approved definition is as follows:

The purpose of an oral appliance is to treat obstructive sleep apnea (OSA), primary snoring, and associated symptoms. Effective oral appliance therapy is best achieved when it is provided by Qualified Dentists. A properly fitted oral appliance worn nightly will decrease the frequency and/or duration of apneas, hypopneas, respiratory effortrelated arousals (RERAs) and/or snoring events. Oral appliances have been demonstrated to improve nocturnal oxygenation as well as the adverse health and social consequences of OSA and snoring. Oral appliances are indicated for patients with mild to moderate OSA and primary snoring. Oral appliances are accepted therapy for patients with severe OSA who do not respond to or are unable or 
unwilling to tolerate positive airway pressure (PAP) therapies. Although oral appliances are typically used as a stand-alone therapy, with some patients they may be prescribed as an adjunct to PAP therapy and/or other treatment modalities for the management of OSA.

Oral appliances refer to mandibular advancement devices because they are the most effective and widely used in clinical practice. The function of an oral appliance is to protrude (advance) and help stabilize the mandible in order to maintain a patent upper airway during sleep.

An oral appliance is custom fabricated using digital or physical impressions and models of an individual patient's oral structures and physical needs. A custom-fabricated oral appliance may include a prefabricated component; however, it is not a primarily prefabricated item that is subsequently trimmed, bent, relined, or otherwise modified. It is made of biocompatible materials and engages both the maxillary and mandibular arches. The oral appliance has a mechanism that advances the mandible in increments of $1 \mathrm{~mm}$ or less with a protrusive adjustment range of at least $5 \mathrm{~mm}$. This mechanism may or may not include fixed mechanical hinges or metallic materials. In addition, reversal of the advancement must be possible. The protrusive setting must be verifiable. The appliance is suitable for placement and removal by the patient or caregiver. It maintains a stable retentive relationship to the teeth, implants, or edentulous ridge, prevents dislodging, and retains the prescribed setting during use.

\subsection{DISCUSSION OF MAJOR CHANGES TO THE DEFINITION}

Five major changes were made to the original definition that relate to oral appliance effectiveness. These changes focused on the physical features and functions of an oral appliance.

\section{An Oral Appliance Must be Made of Materials That Meet Patients' Physical Needs}

An oral appliance must be made of biocompatible materials for it to be considered safe for patient use. ${ }^{8}$ Furthermore, materials must be suitable for an individual patient's oral structure and physical needs. For example, such physical needs may include the need for nonmetallic materials for those with metal hypersensitivities.

Approximately $10 \%$ to $15 \%$ of the population is hypersensitive to metals. ${ }^{9}$ Thus, alternate, biocompatible materials must be used when fabricating oral appliances for such patients. Oral appliance materials that were previously made with metal can now be made with other materials. For instance, the connecting mechanisms in duobloc appliances can be made of elastic, plastic, or even magnets. ${ }^{10}$

\section{A Custom-Fabricated Oral Appliance May Include a Prefabricated Component}

Current evidence indicates that custom oral appliances are superior to prefabricated devices. ${ }^{11-16}$ Custom-made devices have been associated with patient comfort and compliance with treatment. ${ }^{17}$ Overall, custom-made appliances have been associated with improved apnea-hypopnea index (AHI), reduced daytime sleepiness, improved endothelial function, and increased muscle activity. ${ }^{17-26}$ The literature heavily supports use of custom-made oral appliances over prefabricated devices. ${ }^{8}$ Nevertheless, if the device itself is custom made, it may include a prefabricated component (such as the connection mechanism) as long as the device is customized to the patient and not primarily prefabricated. ${ }^{27}$

\section{An Oral Appliance Mechanism is Not Limited to Fixed Mechanical Hinges or Metallic Materials}

Oral appliance designs now feature connecting mechanisms other than fixed mechanical hinges. Additionally, many newer oral appliances feature nonmetallic connectors, which are necessary for those who have OSA and suffer from metal hypersensitivity.

As technology has progressed, a number of nonhinged appliances have been proven effective in treating OSA. For example, AHI was improved using a device that advanced the mandible using elastics connected to Adams clasps. ${ }^{28}$ Another study comparing oral appliances with elastic bands to the same appliance without bands found no significant difference in AHI after use. ${ }^{29}$

Another nonhinged device is connected and adjusted using flexible, nonmetal rods and was associated with significant improvement in OSA symptoms. In one study, $76 \%$ of patients were effectively treated using this device (decrease in $\mathrm{AHI} \geq 50 \%$ ) and $64 \%$ achieved a complete treatment response. ${ }^{22}$ Another study with this oral appliance showed that $56 \%$ of patients using the device achieved treatment response. ${ }^{30}$

Furthermore, an appliance that used ball clasps to protrude the mandible significantly reduced $\mathrm{AHI}$ in one study. This study found that $57 \%$ of patients achieved $\mathrm{AHI}<10$ per hour and $31 \%$ achieved an $\mathrm{AHI}<5$ per hour. Overall, the study concluded that the device was successful in treating OSA in 58\% of patients, excessive daytime sleepiness in 56\%, and snoring in $76 \% .23$ Thus, such studies indicate that appliances featuring 
connecting mechanisms other than fixed mechanical hinges can also effectively treat OSA.

\section{An Oral Appliance Must Prevent Dislodging}

An effective oral appliance must have retention to one or both dental arches. ${ }^{10}$ Lack of proper oral appliance stability can lead to poorer health outcomes. For example, it has been suggested that monobloc could be less effective than duobloc appliances because of poor stability (among other factors). ${ }^{31}$ Thus, the oral appliance must have good retention to the dentition and prevent dislodging.

\section{Lifetime of an Oral Appliance}

The original definition included a clause that stated that an effective oral appliance must "maintain its structural integrity over a minimum of 3 years." 8 After review, it was determined that there was very little evidence outside of the AADSM definition itself that an appliance should last at least 3 years in order for it to be effective. Thus, this sentence was removed from the definition.

\subsection{CONCLUSION}

An oral appliance can be an effective treatment option for those with OSA and snoring. As dental sleep technology rapidly changes, new and effective appliances have emerged. To promote consistency and best treatment practices, the AADSM has updated its definition of an effective oral appliance to reflect current scholarly literature and clinical practice. As further updates in science, technology, and practice develop, future edits to this definition may be made.

\section{CITATION}

Mogell K, Blumenstock N, Mason E, Rohatgi R, Shah S, Schwartz D. Definition of an Effective Oral Appliance for the Treatment of Obstructive Sleep Apnea and Snoring: An Update for 2019. J Dent Sleep Med. 2019;6(3)

\section{REFERENCES}

1. Almeida FR, Lowe AA. Principles of oral appliance therapy for the management of snoring and sleep disordered breathing. Oral Maxillofac Surg Clin North Am. 2009;21(4):413-420. doi:10.1016/j.coms.2009.07.002

2. Rohatgi R, Mogell K, Schwartz DB. Oral appliance therapy should be reimbursed after CPAP intolerance. J Dent Sleep Med. 2019;6(1). doi:10.15331/jdsm.7056

3. Gotsopoulos H, Chen C, Qian J, Cistulli PA. Oral appliance therapy improves symptoms in obstructive sleep apnea. Am J Respir Crit Care Med. 2002;166(5):743-748. doi:10.1164/rccm.200203-2080C

4. Ferguson KA, Ono T, Lowe AA, Keenan SP, Fleetham JA. A randomized crossover study of an oral appliance vs nasal- continuous positive airway pressure in the treatment of mildmoderate obstructive sleep apnea. Chest. 1996;109(5):1269-1275. doi:10.1378/CHEST.109.5.1269

Ferguson KA, Ono T, Lowe AA, al-Majed S, Love LL, Fleetham JA. A short-term controlled trial of an adjustable oral appliance for the treatment of mild to moderate obstructive sleep apnoea. Thorax. 1997;52(4):362-368. doi:10.1136/thx.52.4.362

6. Randerath WJ, Heise M, Hinz R, Ruehle K-H. An individually adjustable oral appliance vs continuous positive airway pressure in mild-to-moderate obstructive sleep apnea syndrome. Chest. 2002;122(2):569-575.

http://www.ncbi.nlm.nih.gov/pubmed/12171833. Accessed May 13, 2019.

7. Tan YK, L'Estrange PR, Luo YM, et al. Mandibular advancement splints and continuous positive airway pressure in patients with obstructive sleep apnoea: A randomized cross-over trial. Eur J Orthod. 2002;24(3):239-249. doi:10.1093/ejo/24.3.239

8. Scherr SC, Dort LC, Almeida FA, et al. Definition of an effective oral appliance for the treatment of obstructive sleep apnea and snoring: a report of the American Academy of Dental Sleep Medicine Consensus Conference Participants. J Dent Sleep Med. 2014;1(1). https://aadsm.org/docs/JDSM.1.1.39.pdf. Accessed December 28, 2018.

9. Saito M, Arakaki R, Yamada A, Tsunematsu T, Kudo Y, Ishimaru $\mathrm{N}$. Molecular mechanisms of nickel allergy. Int J Mol Sci. 2016;17(2):202. doi:10.3390/ijms 17020202

10. Barewal RM, Hagen CC. Management of snoring and obstructive sleep apnea with mandibular repositioning appliances: A prosthodontic approach. Dent Clin North Am. 2014;58(1):159-180. doi:10.1016/j.cden.2013.09.010

11. Morgan TD. Novel approaches to the management of sleepdisordered breathing. Sleep Med Clin. 2016;11(2):173-187. doi:10.1016/j.jsmc.2016.03.001

12. Vanderveken OM, Devolder A, Marklund M, et al. Comparison of a custom-made and a thermoplastic oral appliance for the treatment of mild sleep apnea. Am J Respir Crit Care Med. 2008;178(2):197202. doi:10.1164/rccm.200701-114OC

13. Dioguardi A, Al-Halawani M. Oral appliances in obstructive sleep apnea. Otolaryngol Clin North Am. 2016;49(6):1343-1357. doi:10.1016/j.otc.2016.07.005

14. Serra-Torres S, Bellot-Arcís C, Montiel-Company JM, MarcoAlgarra J, Almerich-Silla JM. Effectiveness of mandibular advancement appliances in treating obstructive sleep apnea syndrome: A systematic review. Laryngoscope. 2016;126(2):507514. doi:10.1002/lary.25505

15. Marklund M, Verbraecken J, Randerath W. Non-CPAP therapies in obstructive sleep apnoea: Mandibular advancement device therapy. Eur Respir J. 2012;39(5):1241-1247. doi:10.1183/09031936.00144711

16. Johnston CD, Gleadhill IC, Cinnamond MJ, Peden WM. Oral appliances for the management of severe snoring: a randomized controlled trial. Eur J Orthod. 2001;23(2):127-134. doi:10.1093/ejo/23.2.127

17. Johal A, Haria P, McLindent M, Manek S, Joury E, Riha R. Readymade versus custom-made mandibular repositioning devices in sleep apnea: a randomized clinical trial. J Clin Sleep Med. 2017;13(2):175-182. doi:10.5664/jcsm.6440

18. Knappe SW, Sonnesen L. Mandibular positioning techniques to improve sleep quality in patients with obstructive sleep apnea: current perspectives. Nat Sci Sleep. 2018;10:65-72. doi:10.2147/NSS.S135760

19. Obstructive Sleep Apnoea Syndrome A Systematic Literature Review The Swedish Council on Technology Assessment in Health Care.; 2007. www.stakes.fi/finohta. Accessed May 13, 2019.

20. Dieltjens M, Vanderveken OM, Hamans E, et al. Treatment of 
obstructive sleep apnea using a custom-made titratable duobloc oral appliance: A prospective clinical study. Sleep Breath. 2013;17(2):565-572. doi:10.1007/s11325-012-0721-3

Itzhaki S, Dorchin H, Clark G, Lavie L, Lavie P, Pillar G. The effects of 1-year treatment with a herbst mandibular advancement splint on obstructive sleep apnea, oxidative stress, and endothelial function. Chest. 2007;131(3):740-749. doi:10.1378/chest.06-0965

Vecchierini M-F, Attali V, Collet J-M, et al. A custom-made mandibular repositioning device for obstructive sleep apnoeahypopnoea syndrome: the ORCADES study. Sleep Med. 2016;19:131-140. doi:10.1016/J.SLEEP.2015.05.020

23. Van Haesendonck G, Dieltjens M, Hamans E, Braem MJ, Vanderveken OM. Treatment efficacy of a titratable oral appliance in obstructive sleep apnea patients: a prospective clinical trial. BENT. 2016;12(1):1-8. http://www.ncbi.nlm.nih.gov/pubmed/27097387. Accessed October 30, 2018.

24. Johal A, Gill G, Ferman A, McLaughlin K. The effect of mandibular advancement appliances on awake upper airway and masticatory muscle activity in patients with obstructive sleep apnoea. Clin Physiol Funct Imaging. 2007;27(1):47-53. doi:10.1111/j.1475-097X.2007.00714.x

25. Ngiam J, Balasubramaniam R, Darendeliler M, Cheng A, Waters $\mathrm{K}$, Sullivan C. Clinical guidelines for oral appliance therapy in the treatment of snoring and obstructive sleep apnoea. Aust Dent J. 2013;58(4):408-419. doi:10.1111/adj.12111

26. Ramar K, Dort LC, Katz SG, et al. Clinical Practice Guideline for the Treatment of Obstructive Sleep Apnea and Snoring with Oral Appliance Therapy: an update for 2015. J Clin Sleep Med. 2015;11(7):773-827. doi:10.5664/jcsm.4858

27. Local Coverage Determination (LCD): Oral Appliances for Obstructive Sleep Apnea (L33611); 2018. https://med.noridianmedicare.com/documents/2230703/7218263/ Oral+Appliances+for+Obstructive+Sleep+Apnea+LCD+and+PA/ dc994aa8-c706-438b-9e31-db18a6be1358. Accessed May 13, 2019.

28. Teixeira AO de B, Abi-Ramia LBP, Almeida MA de O. Treatment of obstructive sleep apnea with oral appliances. Prog Orthod. 2013;14(1):1-9. doi:10.1186/2196-1042-14-10

29. Norrhem N, Marklund M. An oral appliance with or without elastic bands to control mouth opening during sleep - a randomized pilot study. Sleep Breath. 2016;20(3):929-938. doi:10.1007/s11325016-1312-5
30.

Isacsson G, Fodor C, Sturebrand M. Obstructive sleep apnea treated with custom-made bibloc and monobloc oral appliances: a retrospective comparative study. Sleep Breath. 2017;21(1):93-100. doi:10.1007/s11325-016-1377-1

31. Marty M, Lacaze O, Arreto CD, et al. Snoring and obstructive sleep apnea: objective efficacy and impact of a chairside fabricated mandibular advancement device. J Prosthodont. 2017;26(5):381386. doi:10.1111/jopr.12401

\section{SUBMISSION AND CORRESPONDENCE INFORMATION}

\section{Submitted in final revised form June 7, 2019 Accepted for publication June 7, 2019}

Address correspondence to: Kenneth Mogell, DMD, D.ABDSM, \#212 South Building, 2900 N Military Trl, Boca Raton, FL 33431; Email: drmogell@gmail.com

\section{DISCLOSURE STATEMENT}

Dr. Mogell reports being on the editorial advisory board of Sleep Review and receiving an honorarium to present at the American Academy of Oral Medicine Meeting in 2017. Dr. Mason reports being an unpaid member of the Board of Directors for the Virginia Academy of Sleep Medicine, accepting honoraria and gifts for Prosomnus speaking engagements, and being involved in speaking engagements for "thedentalspeaker.com" and NDX Laboratory. Dr. Rohatgi reports serving as part of an advisory group for Prosomnus. Dr. Schwartz reports serving as part of an advisory group for Prosomnus and having a financial stake in Prosomnus. Dr. Shah reports giving paid lectures for Sleep Group Solutions. Dr. Blumenstock has no conflicts of interest to disclose. 